\title{
Front Matter: Volume 10264
}

, "Front Matter: Volume 10264," Proc. SPIE 10264, The Aviation Security Problem and Related Technologies: A Critical Review, 1026401 (28 December 1992); doi: $10.1117 / 12.2284733$

SPIE. Event: San Diego '92, 1992, San Diego, CA, United States 


\section{Contents}

vii Preface

3 Aviation security and Pan Am 103

R. G. Monetti, Victims of Pan Am Flight 103

11 Potential detection problems: nonnitrogen-based explosives

W. W. Bannister, University of Massachusetts/Lowell; J. C. Oxley, New Mexico

Institute of Mining and Technology

44 Forensic analysis of explosives

F. W. Whitehurst, Federal Bureau of Investigation

77 Commercial aircraft vulnerability to terrorism

J. A. Gatto, Aviation Security Research \& Development Service,

FAA Technical Center

93 Dog-handler team as a detection system for explosives: a tail to be told

L. J. Myers, Auburn University

104 Visualization and imaging

R. Lanza, FAA Technical Center and Massachusetts Institute of Technology

126 Detection of explosive materials using nuclear radiation: a critical review

E. M. A. Hussein, University of New Brunswick (Canada)

137 Nuclear technologies for explosives detection

C. J. Bell, Aviation Security Research \& Development Service, FAA

Technical Center

167 Crossing the barrier between the laboratory working model and the practicable production model

W. A. Curby, Aviation Security Research \& Development Service,

FAA Technical Center

182 Probabilistic risk assessment: a tool for aviation security decision making

N. O. Siu, Massachusetts Institute of Technology

212 Aviation security research and development effort at the FAA

P. Polski, L. T. Powell, Jr., Aviation Security Research \& Development Service, FAA

Technical Center

The Aviation Security Problem and Related Technologies: A Critical Review, edited by Wagih H. Makky, Proc. of SPIE Vol. 10264 (Vol. CR42), 1026401 · ( ) (1992) 2017 SPIE CCC code: 0277-786X/17/\$18 · doi: 10.1117/12.2284733 


\section{Preface}

In recent years the security problem in the aviation industry has assumed such magnitude that it now virtually defines the way the industry conducts its business. The implications of this problem have far-reaching business, economic, and operational consequences for the industry and the general public. Some experts argue that one of the main reasons for the demise of Pan American Airlines early in 1992 was the unfortunate terrorist incident that destroyed Flight 103 over Scotland and the subsequent loss of international business travel the company suffered as a result. Whether or not Pan Am was actually declining before the incident, it is certain that it never recovered after this terrorist act.

Security measures are apparent in airports, aboard aircraft, and in every venue associated with air travel. Aviation security measures vary greatly according to operational and environmental requirements, operators, geographical considerations, and other economic and political factors. The type, magnitude, and frequency of terrorist acts against international civil aviation have steadily changed over the past few decades. There is not a single obvious method to define or categorize all terrorist activities against civil aviation. Therefore, there is not an easy approach to deal with the aviation security problem. Different national authorities have historically used different approaches. As a rule, these methods have involved combinations of preventive measures, punitive measures, political considerations, and intelligence, as well as other direct and indirect measures.

Preventive measures consist mostly of methods and techniques to discover the existence of a threat to a specific target within the civil aviation system before it can take place. These can be technical and nontechnical methodologies. By their very nature, only technical means and methodologies lend themselves to quantitative analysis and measurements. Technical means for combating terrorist threats to civil aviation are mainly directed at the detection of concealed energetic materials in general in passengers' luggage, on passengers, and in anything that eventually ends up on board an aircraft. They are also concerned with containing an explosion on an aircraft if detection methods were not as adequate as they should have been.

This critical review is concerned only with technical means and approaches in dealing with the aviation security problem. It is probably the only comprehensive collection of expert opinion on the subject presently in existence. There is obviously more to combating terrorism against civil aviation than technical means. 
The reviews appearing in this book have been carefully chosen from among presentations and critiques given at the Aviation Security Problem and Related Technologies conference cosponsored by the U.S. Federal Aviation Administration held in San Diego, 19-20 July 1992. This conference was the culmination of an ongoing effort to measure and adequately comprehend the aviation security problem from a technology standpoint. It was preceded by several activities sponsored by the FAA such as the "Intensive Short Course of Physics and Chemistry of Explosives" held in Ocean City, New Jersey, in May 1991, the "Nondestructive Probing Techniques for Bulk Materials" Engineering Problems and Solutions Workshop at the 1991 SPIE San Diego meeting, the "First International Symposium on Explosive Detection Technology" held in Atlantic City, New Jersey, 13-15 November 1991, the "National Energetic Materials Workshop and Study Groups" held in Avalon, New Jersey, 14-17 April 1992, and the "Explosives Effects Workshop" held in Pleasantville, New Jersey, 29 April-1 May 1992. A workshop discussing Neural Networks Applications in Aviation Security was held in cooperation with the Center for Computer Aids for Industrial Productivity (CAIP) at Rutgers University in East Brunswick, New Jersey, 27-29 October 1992. A six-conference stand-alone symposium on Aviation Security Technology to be held in Vienna, Austria, in October 1993 is currently in the planning stages.

This critical review addresses three approaches to the problem: (1) chemistry, physics, and aftereffects of and aircraft vulnerability to the explosive material itself; (2) techniques for detection of explosives, both passively and with the help of a probe; and (3) operational considerations related to technical development of such techniques and the effects their deployment will have on the airport environment.

An introduction to the Pan Am Flight 103 incident from a victim's point of view, although nontechnical in nature, is probably an appropriate reminder to all concerned of the seriousness of the problem at hand. This volume begins with such a reminder by Robert Monetti, himself the father of one of the victims.

Energetic materials and explosives are discussed in the paper by Bannister and Oxley, giving an overview of the problem from an explosives point of view. It explains how energy can be released in large enough quantities to cause damage and potential destruction of an aircraft. The aftereffects of an explosion are discussed in the paper by Whitehurst, while an overview of the vulnerability of commercial aircraft to terrorist acts is given by Gatto.

Potential techniques to be employed in detecting energetic materials are addressed in the papers by Myers, Lanza, and Bell. Myers discusses detection from the passive-systems point of view, using dogs. Probing and imaging techniques are 
addressed in the papers by Lanza and Bell. Nuclear techniques for detecting concealed explosives are reviewed by Hussein. Curby discusses the crucial step of translating research and development efforts in a laboratory setting into an actually deployable system. Siu makes a probabilistic risk assessment argument for the establishment of an Overall Aviation Security System. Paul Polski, director of the Aviation Security R\&D Service, and Leo Powell, manager of the Security Technology Division, both of the FAA, give a description of the organizational efforts undertaken within the FAA to solve the aviation security problem.

From all indications, terrorist acts against civil aviation form a long-term problem that will stay with us for the foreseeable future. This Critical Review has been produced in the hope that it will contribute to the eventual solution of the security problem. It is certainly hoped that it will at least help accelerate the maturity of the technical approaches.

I would like to thank all the authors for their contributions and cooperation in making this valuable reference source available to the public at the earliest possible time. I would also like to acknowledge the help and encouragement I received from Terry Montonye, SPIE Technical Director, who suggested this critical review in the first place. The SPIE publications staff were also of great assistance, and thanks are due to all.

\section{Wagih H. Makky}

Aviation Security R\&D Service, FAA Technical Center 